\title{
Poly(vinyl amine) microparticles derived from $N$-Vinylformamide and their versatile use
}

\author{
Sahin Demirci ${ }^{1,2} \cdot$ S. Duygu Sütekin ${ }^{3,4}$. Saliha B. Kurt ${ }^{2}$. Olgun Güven ${ }^{3}$. \\ Nurettin Sahiner ${ }^{1,2,5,6}$ (D)
}

Received: 11 March 2021 / Revised: 4 August 2021 / Accepted: 27 August 2021

(c) The Author(s), under exclusive licence to Springer-Verlag GmbH Germany, part of Springer Nature 2021

\begin{abstract}
Cationic polymers with primary amine groups that can easily be functionalized or coupled with substrates by complexation or hydrogen bonding are especially advantageous in preparing particles for biomedical applications. Poly(vinyl amine) (PVAm) is a cationic polyelectrolyte containing the highest number of primary amine groups among any other polymers. Here, we introduce a general method in synthesizing PVAm microparticles via a surfactant-free water-in-oil emulsion technique using cyclohexane as the oil phase and aqueous PVAm solution as the dispersed phase. PVAm particles were prepared to employ two different bifunctional chemical crosslinkers, divinyl sulfone (DVS) and poly(ethylene glycol) diglycidyl ether (PEGGE). The prepared particles were further treated with $\mathrm{HCl}$ to protonate the amine groups of PVAm within particles. The effect of crosslinker types and $\mathrm{pH}$ on the hydrolytic degradation of PVAm particles were also investigated at three different solution pHs, 5.4, 7.4, and 9, to simulate the skin, blood, and intestinal $\mathrm{pH}$ environments, respectively. The blood compatibility of the PVAm particles was evaluated by in vitro hemolysis and blood clotting assays. Furthermore, antifungal and antibacterial efficacy of PVAm-based particles and their protonated forms were tested against $C$. albicans yeast and E. coli, S. aureus, B. subtilis, and P. aeruginosa bacterial strains.
\end{abstract}

Keywords Antibacterial/antifungal material · Poly(vinyl amine) $\cdot$ Polymeric microparticles $\cdot$ Blood compatible

Nurettin Sahiner

sahiner71@gmail.com

Extended author information available on the last page of the article 


\section{Introduction}

Polymers bearing amine groups are restorative materials used in academia and industry due to their high reactivity, ease of derivatization of the amino groups, and the cationic nature at specific pHs. Poly(vinyl amine) (PVAm) is a cationic polyelectrolyte containing the highest number of primary amine groups among any other polymers. PVAm cannot be directly synthesized, however, from the implied monomer vinylamine due to its instability [1]. A sustained effort has been made during the past 50 years to synthesize PVAm from the hydrolysis of $N$-vinyl phthalimide, poly( $N$-vinyl acetamide), etc. Recently, commercially available $N$-vinyl formamide has been considered as an essential precursor in the preparation of poly(vinylamine) [2].

PVAm presents a high affinity for many substances, especially anionic ones, due to its cationic nature, high hydrogen bonding, and complex formation capacity. Therefore, it is often used in catalysis [3], surface modification [4], metal complexation [5], paper strengthening [6], wastewater treatment [7], $\mathrm{CO}_{2}$ capture [8], and so on. Biomedical applications of PVAm include its use in gene delivery and transfection $[9,10]$, controlled drug delivery [11], and antimicrobial and antibacterial polymers $[12,13]$.

Cationic primary, secondary, tertiary, and quaternary ammonium groups are often preferred in antimicrobial cationic polymers. Among these, quaternary ammonium groups are valuable in terms of reduced $\mathrm{pH}$ dependency. In contrast, polymers carrying primary, secondary, or tertiary ammonium groups have been shown to exhibit higher antimicrobial effects and low hemolytic activity $[14,15]$. In a study conducted by Palermo and Kuroda, it was stated that structures with primary amine groups showed the highest antimicrobial activity against Escherichia coli and the highest selectivity on red blood cells (RBCs) as compared to facilities with tertiary amine and quaternary ammonium groups [16]. Therefore, PVAm represents a promising alternative to other cationic amine-containing polymers commonly preferred in biomedical applications such as polyethyleneimine (PEI) [17].

Microparticles with high primary amine contents are favorable in biomedical applications due to the versatility and functionality of the primary amine group. Hence, various PVAm particles with different sizes and morphologies were already prepared in microgel [18-20], nano gel [10, 21], and core-shell structures [22].

The synthesis of linear poly(vinylamine) from polymerization and hydrolysis of $N$-vinyl formamide in acidic and basic conditions was already reported in the literature, suggesting that acidic hydrolysis generates cationic polymers with the overall limited conversion due to electrostatic repulsion among ammonium groups. On the other hand, alkaline conditions develop free amine groups with almost $100 \%$ conversion [23, 24]. Therefore, basic hydrolysis was selected in this study to transform amide groups into amine groups in a high yield.

In this study, we describe the synthesis of PVAm microparticles using a surfactant-free water-in-oil emulsion technique by dispersing aqueous PVAm 
solution within cyclohexane oil phase and the crosslinking of PVAm macromolecules in the aqueous phase using divinyl sulfone (DVS) or poly(ethylene glycol) diglycidyl ether (PEGGE) as bifunctional chemical crosslinkers. PVAm particles were further treated with $\mathrm{HCl}$ to obtain protonated forms of amine groups in the particle network. Characterization of PVAm-based particles was performed by optical microscopy, scanning electron microscopy (SEM), and Fourier transform infrared spectroscopy (FT-IR). Thermal stabilities and fluorescent properties of PVAm-based particles and their protonated forms crosslinked with either DVS or PEGGE were examined with thermogravimetric analysis (TGA) and UV/Vis and fluorescent spectroscopies. The hydrolytic degradation of PVAm particles at $\mathrm{pH}$ values of 5.4, 7.4, and 9 was investigated. The blood compatibility and antifungal and antibacterial properties against various microorganisms were further tested to ascertain the potential biomedical utilization of PVAm-based particles.

\section{Experimental}

\section{Materials}

$\mathrm{N}$-Vinylformamide (NVF, 98\%, Aldrich) was used as the monomer, and 2,2'-azobis(2-methylpropionamidine) dihydrochloride (AIBA, 97\%, Aldrich) was used as the thermal initiator to synthesize poly( $N$-vinyl formamide) (PNVF). Acetone (99.75\%, Sigma Aldrich) was used for the precipitation of the prepared PNVF polymers. Sodium hydroxide ( $\mathrm{NaOH}$, pellets ACS/Reag. Ph. Eur., VWR Chemicals) was used for the basic hydrolysis reaction of PNVF polymer. Divinyl sulfone (DVS, 98\%, Sigma Aldrich) and poly(ethylene glycol) diglycidyl ether (PEGGE, $\mathrm{M}_{\mathrm{n}}: 500$, 99\%, Sigma Aldrich) were used as crosslinkers, and cyclohexane (99.8\%, Sigma Aldrich) was used as the solvent medium in the particle preparation. Nutrient agar and nutrient broth were procured from Merck (Germany) and used as microbial growth media. Escherichia coli ATCC 8739, Staphylococcus aureus ATCC 6538, Bacillus subtilis, Pseudomonas aeruginosa, and Candida albicans strains were obtained from the Microbiology Department of the School of Medicine at Canakkale Onsekiz Mart University. Calcium chloride $\left(\mathrm{CaCl}_{2}, 99 \%\right.$, Merck) was used for blood clotting experiments, and sodium chloride ( $\mathrm{NaCl}, 99 \%$, Merck) was used in the preparation of the physiological saline solution. Double distilled water (DDW, GFL 2108), $1.6 \mu \mathrm{s} / \mathrm{cm}$, was used in all experiments unless otherwise specified.

\section{Synthesis of PNVF}

Synthesis of PNVF polymers was carried out via the free radical polymerization technique following the literature [23]. Briefly, $5 \mathrm{~mL}$ of NVF monomer was dispersed in $40 \mathrm{~mL}$ of DDW by stirring at room temperature (RT) for about $5 \mathrm{~min}$. Then, the monomer solution in a round bottom flask was immersed into an oil bath set at $70{ }^{\circ} \mathrm{C}$ followed by the addition of $5 \mathrm{~mL}$ of aqueous initiator solution containing $1 \%$ AIBA concerning the number of moles of NVF. Polymerization reaction 
proceeded for two h under $800 \mathrm{rpm}$ continuous mechanical stirring at $70{ }^{\circ} \mathrm{C}$. Afterward, PNVF polymers obtained were precipitated in $1 \mathrm{~L}$ of acetone by dropwise addition of the reaction medium. Finally, the precipitates were dried at $80{ }^{\circ} \mathrm{C}$ and stored in moisture-tight capped tubes until use.

\section{Hydrolysis of PNVF in basic medium}

Amide groups of PNVF chains were exposed to hydrolyzation in basic conditions to yield poly(vinyl amine) (PVAm) polymers in accord with the earlier reports in the literature with some modifications [24]. In brief, 10\% basic PNVF solution was prepared by dissolving $1.0 \mathrm{~g}$ of the synthesized PNVF in $9 \mathrm{~mL}$ of $2 \mathrm{M} \mathrm{NaOH}$ solution. Then, the reaction medium was transferred into a temperature-regulated oil bath at $80{ }^{\circ} \mathrm{C}$ and continued stirring under $500 \mathrm{rpm}$ for four h to trigger PVAm conversion. Sodium formate (HCOONa), produced as a by-product during the basic hydrolysis of PNVF, was not removed prior to the synthesis of PVAm microparticles. Subsequently, PVAm solution was cooled under running tap water and stored in an amber glass vial at room temperature (RT).

\section{Synthesis of PVAm particles}

The crosslinking of PVAm as particles was achieved in a surfactant-free water-in-oil emulsion system obtained by dispersing aqueous PVAm solution in cyclohexane and subsequent addition of two different bifunctional crosslinkers, DVS and PEGGE, separately to attain two different types of PVAM particles [25]. The PVAm solution obtained by the basic hydrolysis of PNVF was directly used in the preparation of PVAm particles. Shortly, $500 \mu \mathrm{L}$ of $0.1 \mathrm{~g} / \mathrm{mL}$ PVAm containing aqueous solution was added into $50 \mathrm{~mL}$ of cyclohexane and homogenized for $1 \mathrm{~min}$ at an 8,000 rpm mixing rate. Then, the solution of $2 \mathrm{~mol} \%$ DVS based on the mole of NVF was added into the emulsion and stirred for $10 \mathrm{~min}$ at 18,000 rpm at RT. After gravitational precipitation, the DVS-crosslinked PVAm (PVAm-1) particles were carefully decanted from the cyclohexane/water medium without disturbing the precipitate. The PVAm-1 particles were washed three times with acetone, and then washed with ethanol and water for one time each, and finally two times with acetone by centrifugation at 10,000 $\mathrm{rpm}$ for $5 \mathrm{~min}$. The by-product of basic hydrolysis of PNVF, sodium formate, was also removed during the washing steps of the particles. The purified PVAm-1 particles were then dried with a hot air gun and capped in closed tubes until further use.

Similar steps were pursued in the synthesis of PEGGE-crosslinked PVAm (PVAm-2) particles with minor modifications. Concisely, $500 \mu \mathrm{L}$ of $0.1 \mathrm{~g} / \mathrm{mL}$ aqueous PVAm solution was added and dispersed into $50 \mathrm{~mL}$ of cyclohexane at $8000 \mathrm{rpm}$ mixing for $1 \mathrm{~min}$. Afterward, 5\% PEGGE with respect to the mole of NVF was added dropwise into the emulsion and stirred at $800 \mathrm{rpm}$ and $50{ }^{\circ} \mathrm{C}$ for two h. The PVAm-2 particles thus prepared were separated from the cyclohexane/ water emulsion by centrifugation at $10,000 \mathrm{rpm}$ for $5 \mathrm{~min}$, then washed, dried, and stored as described in the preparation of PVAm-1 particles. 
Moreover, for protonation of amine groups of both PVAm-1 and PVAm-2 particles, $2.0 \mathrm{~g}$ of each type of particle was treated with $250 \mathrm{~mL}$ of $1 \mathrm{M} \mathrm{HCl}$ solution, then washed with water and acetone twice by centrifugation and dried as described earlier. The prepared PVAm-1-HCl and PVAm-2- $\mathrm{HCl}$ particles were stored in moisture-free tubes for further use.

\section{Characterization}

Fourier transform infrared spectroscopy (FT-IR, Perkin Elmer spectrum 100) was used in the functional group analysis of synthesized PNVF, PVAm, neutral, and protonated PVAm particles. FT-IR spectra were recorded at $4 \mathrm{~cm}^{-1}$ resolution in $4000-650 \mathrm{~cm}^{-1}$ wavenumber range via the attenuated total reflectance (ATR) method.

Thermogravimetric thermogram of the linear PVAm and crosslinked PVAm particles were taken between 55 and $1000{ }^{\circ} \mathrm{C}$ at a heating rate of $10{ }^{\circ} \mathrm{C} \mathrm{min}^{-1}$ under continuous $\mathrm{N}_{2}$ purge with $100 \mathrm{~mL} \mathrm{~min}^{-1}$ flow rates via a thermogravimetric analyzer (TGA, SII TG/DTA 6300, Exstar). About 3-5 mg of each sample was placed into ceramic TGA pans, and the weight loss was determined as a function of temperature.

Zeta potentials of PVAm-1 and PVAm-2 particles at different $\mathrm{pH}$ values were measured by using a zeta potential analyzer (Malvern Zetasizer, Nano ZS series, Brookhaven Inc.) in $0.1 \mathrm{M} \mathrm{NaCl}$ solution in DDW water. The $\mathrm{pH}$ of the particle suspension was arranged to 2.0 by using $0.1 \mathrm{M} \mathrm{HCl}$, and the $\mathrm{pH}$ was varied in the 2-12 range by the dropwise addition of $0.1 \mathrm{M} \mathrm{NaOH}$.

The fluorescence measurements of PVAm and PVAm-based particles were conducted in their aqueous solution/suspension by using a fluorescence spectrometer (Thermo Lumina). The size and morphology of PVAm-based particles were evaluated by optical microscopy (Olympus BX53F) and environmental scanning electron microscopy (FEI Quanta 200F ESEM) operating at $10 \mathrm{kV}$. For the SEM measurements, particles were first dispersed in ethanol solution and cast onto carbon grids.

\section{pH-Dependent hydrolytic degradation of PVAm particles}

To determine the effect of crosslinker types and $\mathrm{pH}$ on the hydrolytic degradation of PVAm particles, degradation studies were performed at three different $\mathrm{pH}$ values as 5.4, 7.4, and 9 to simulate $\mathrm{pH}$ of the skin, blood, and intestinal environments, respectively. Dry PVAm particles weighing about $30 \mathrm{mg}$ were dispersed in $1.0 \mathrm{~mL}$ of proper buffer solution and transferred into a dialysis membrane (molecular weight cut off $\geq 12,000 \mathrm{Da}$, Aldrich). The dialysis membranes were then placed in a capped tube containing $29 \mathrm{~mL}$ buffer solutions to make the final volume $30 \mathrm{~mL}$ and incubated in a water bath at $37^{\circ} \mathrm{C}$ and $350 \mathrm{rpm}$ of agitation during the degradation studies. The extent of hydrolytic degradation was spectrophotometrically determined using UV/Vis spectrophotometer (T80+, PG Instrument Limited) by measuring the amount of degraded PVAm permeated into the buffer solutions. Previously prepared calibration curves at $\mathrm{pH} 7.4$ and $\mathrm{pH} 9.0$ buffer solutions at $305 \mathrm{~nm}$ were used in the quantification of degradation. Since the calibration of PVAm could not be made at 
$\mathrm{pH} 5.4$ due to precipitation of the polymer, the degradation of the particles at $\mathrm{pH} 5.4$ was followed from the calibration curve at $\mathrm{pH} 7.4$ by adjusting the $\mathrm{pH}$ of the sample fractions to 7.4. All hydrolytic degradation studies were performed in triplicates, and the results were given as means with relative standard deviations.

\section{Blood compatibility}

Haemocompatibility of PVAm particles was evaluated by in vitro hemolysis and blood clotting assays upon granting the institutional approval from the Ethical Committee of Canakkale Onsekiz Mart University (2011-KAEK27/2020-E.2000045671). The blood was drawn from healthy individuals on voluntary donation and collected in EDTA containing hemogram tubes and used within 20 min after donation. The hemolysis and blood clotting assays of PVAm particles were conducted according to our previous reports [26].

\section{Hemolysis assay}

For the hemolysis test, $1 \mathrm{mg} / \mathrm{mL}$ concentration was chosen for neutral and protonated PVAm particles. $100 \mathrm{mg}$ of PVAm particles were suspended in $10 \mathrm{~mL}$ of $0.9 \%$ saline solution, and $1 \mathrm{~mL}$ aliquots of this suspension were further dispersed in isotonic saline solution with a final volume of $9.8 \mathrm{~mL}$. Then, PVAm particles were interacted with $0.2 \mathrm{~mL}$ of isosaline diluted whole blood (blood: saline solution, 2:2.5) and incubated at $37^{\circ} \mathrm{C}$ for $1 \mathrm{~h}$. The isotonic saline solution and DDW, $9.8 \mathrm{~mL}$ of each, were, respectively, used as negative and positive controls in the absence of particles. Following the incubation of samples, $2 \mathrm{~mL}$ fractions of $10 \mathrm{~mL}$ particleblood suspensions were centrifuged at $1340 \mathrm{rpm}$ for $5 \mathrm{~min}$. Afterward, the hemoglobin content of supernatants was determined by measuring absorbance of the samples, and the \% hemolysis index of the particles was calculated using Eq. 1.

$$
\text { Hemolysis index } \left.(\%)=\left(A_{\text {sample }}-A_{\text {negative }}\right) / A_{\text {positive_- }} A_{\text {negative }}\right) \times 100
$$

where $A_{\text {sample }}$ is the absorbance of blood containing PVAm particles, $A_{\text {negative }}$ and $A_{\text {positive }}$ are the absorbance of blood incubated with only the isotonic solution and DDW, respectively.

\section{Blood clotting assay}

For the blood clotting assay, $1 \mathrm{~mL}$ of $100 \mathrm{mg} / \mathrm{mL}$ PVAm particle suspension prepared in $0.9 \%$ isotonic saline solution was dropped at the bottom of the $50 \mathrm{~mL}$ falcon tubes. Then, $3 \mathrm{~mL}$ of EDTA containing whole blood was added to $0.24 \mathrm{~mL}$ of $0.2 \mathrm{M} \mathrm{CaCl}_{2}$ solution while synchronously starting a stopwatch; $0.27 \mathrm{~mL}$ of this suspension was added on PVAm particle-containing falcon tubes. With the $10 \mathrm{~min}$ particle-blood interaction, $10 \mathrm{~mL}$ of DDW was added to the falcon tubes and centrifuged at $540 \mathrm{rpm}$. After the centrifugation, the clots that might be formed as a result of PVAm particle-blood interactions were separated by carefully transferring 
the supernatant of the samples into $40 \mathrm{~mL}$ water in separate falcon tubes. Then, the samples were incubated for one $\mathrm{h}$ in a shaking water bath at $37^{\circ} \mathrm{C}$. After the incubation period, the absorbance of the samples at $542 \mathrm{~nm}$ was recorded, and the \% blood clotting index was calculated according to Eq. 2.

$$
\text { Blood clotting index }(\%)=\left(A_{\text {sample }} / A_{\text {control }}\right) \times 100
$$

where $A_{\text {sample }}$ is the absorbance of particle-drug suspension and $A_{\text {control }}$ is the $0.27 \mathrm{~mL}$ blood suspended in $50 \mathrm{~mL}$ of DDW.

\section{Antimicrobial activity assessment of PVAm particles}

Antimicrobial effects of PVAm-HCl as a linear polymer, PVAm-1 and PVAm-2 particles, and their protonated forms were tested against commonly used yeast and bacterial strains such as $C$. albicans (ATCC 10,231), E. coli (gram -, ATCC 8739), S. aureus (gram +, ATCC 6538), B. subtilis (gram +, ATCC 6633), and P. aeruginosa (gram -, ATCC 10,145) by broth microdilution method. In the antimicrobial assay, $100,50,25$, and $10 \mathrm{mg}$ triplicate fractions of each particle were sterilized under UV light at $420 \mathrm{~nm}$ by $3 \mathrm{~min}$ exposure and suspended in $10 \mathrm{~mL}$ of nutrient broth with a final concentration of $10,5,2.5$, and $1 \mathrm{mg} / \mathrm{mL}$. Afterward, $100 \mu \mathrm{L}$ of microbial suspensions previously adjusted to $0.5 \mathrm{McFarland}$ turbidity were inoculated into growth media supplemented with PVAm particles $(1-10 \mathrm{mg} / \mathrm{mL})$ and incubated at $35^{\circ} \mathrm{C}$ for $24 \mathrm{~h}$. Following the incubation, $100 \mu \mathrm{L}$ of microbial cultures were seeded on agar plates, then incubated for $24 \mathrm{~h}$, and viable colonies were counted. Respectively, potato-dextrose agar and nutrient agar plates were used for the yeast and bacterial strains, and $0.9 \%$ saline solution was used for dilution to count colonies.

\section{Results and discussion}

\section{Synthesis and hydrolysis of PNVF}

Synthesis of PVAm from direct polymerization of vinyl amine monomer is not possible due to the instability of the monomer. In this regard, various experimental procedures have been reported in the literature to synthesize PVAm from different sources [1, 27-29]. Hydrolysis of PNVF in the acidic or basic medium is the commonly established method to synthesize PVAm polymers [23]. The base hydrolysis of PNVF was reported to accomplish complete conversion of amide groups to amine groups in $12 \mathrm{~h}$ [24], whereas the formation of protonated amines and proton hydrates were found to be limiting factors in acid-mediated hydrolysis, hence yielding lower conversions. The effect of parameters such as the molar ratio of acid or base to amide groups and temperature was revealed in detail [24]. Although higher temperatures yield higher initial conversion rates, the final degree of hydrolysis at equilibrium was revealed to depend only on acid or base to amide ratios [24]. Likewise, the kinetics and modeling of free radical polymerization of NVF were thoroughly investigated in bulk and aqueous solution by Gu et al. [23]. 


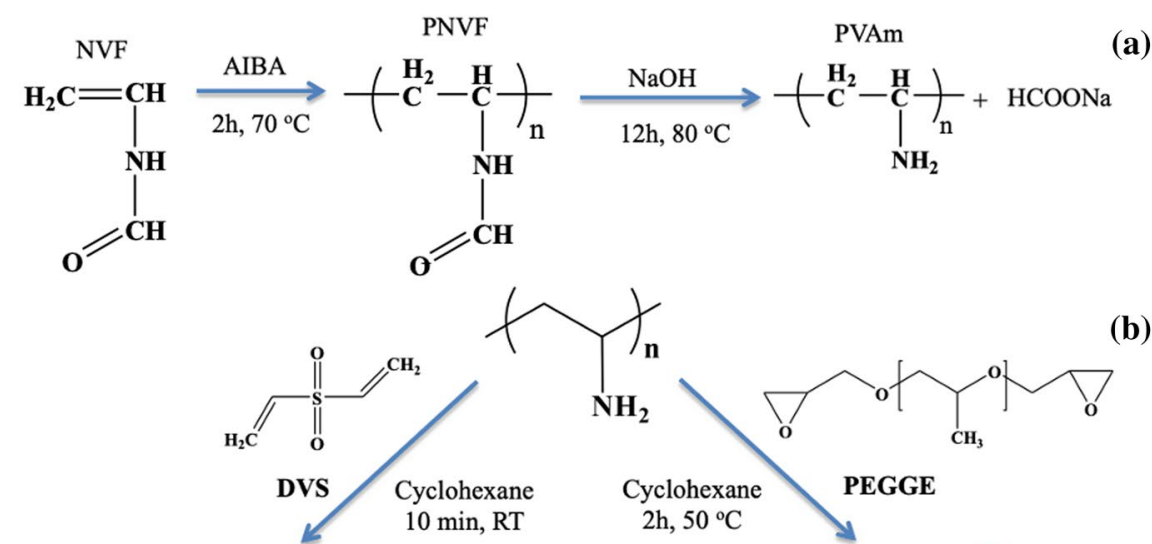

(a)
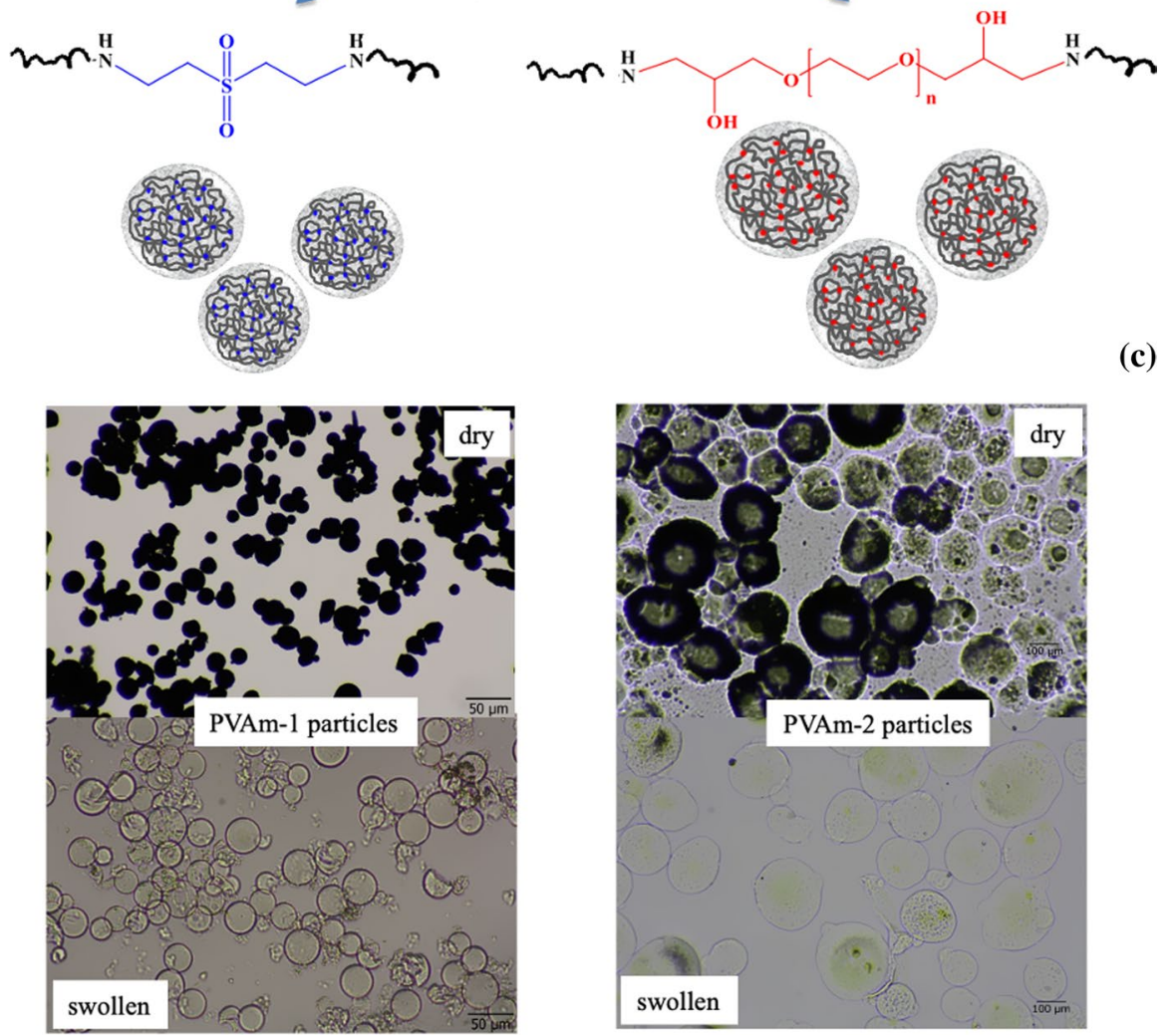

Fig. 1 a The schematic presentation of synthesis route of PVAm starting from NVF, b synthesis of PVAm-1 and PVAm-2 particles, and $\mathbf{c}$ optical microscope images of PVAm-1 and PVAm-2 particles in dried and swollen states

In this study, the preparation of PVAm was carried out by hydrolysis of PNVF in a basic medium with the reaction route presented in Fig. 1a. PNVF was prepared by free radical polymerization of NVF in the presence of AIBA as initiator at $70{ }^{\circ} \mathrm{C}$, 
and the initial viscosity of the solution appeared to increase after $2 \mathrm{~h}$ of polymerization. The number and weight average molecular weight and dispersity of PNVF were determined by SEC as 10,750 $\mathrm{g} \mathrm{mol}^{-1}, 31,500 \mathrm{~g} \mathrm{~mol}^{-1}$, and 2.93, respectively, as given in Fig. S1. The prepared PNVF polymers were hydrolyzed in basic conditions as described in the literature [24]. The structural characterization of PNVF and hydrolyzed forms, PVAm was performed by means of ${ }^{1} \mathrm{H}$ and ${ }^{13} \mathrm{C}$ NMR spectroscopies in details and reported in our previous study [37]. The degree of hydrolysis was also determined from ${ }^{1} \mathrm{H}$ NMR spectrum as $98.4 \%$ suggesting that most of the NVF groups were converted into VAm moieties [37].

The FT-IR spectra of NVF molecules, PNVF, and PVAm polymers are given in Fig. S2. The most distinct characteristic peaks of NVF monomers are observed at $1666 \mathrm{~cm}^{-1}$ for vinyl groups, $1638 \mathrm{~cm}^{-1}$ for $\mathrm{C}=\mathrm{O}$ of amide groups, and also at $1509 \mathrm{~cm}^{-1}$ for $\mathrm{N}-\mathrm{H}$ bending of amide groups, respectively. On the other hand, the vinyl peaks at $1666 \mathrm{~cm}^{-1}$ were found to disappear in the spectrum of PNVF, as expected. Additionally, the $\mathrm{C}=\mathrm{O}$ peaks from amide groups shifted to $1643 \mathrm{~cm}^{-1}$, and $\mathrm{N}-\mathrm{H}$ bending peaks of amide groups shifted to $1519 \mathrm{~cm}^{-1}$, respectively [30]. Moreover, the $\mathrm{C}=\mathrm{O}$ peaks of amide groups disappeared in the FT-IR spectrum of PVAm, and the $\mathrm{N}-\mathrm{H}$ bending peaks from $\mathrm{NH}_{2}$ groups were observed at around $1600 \mathrm{~cm}^{-1}$. These observations were collectively in line with the literature [24].

The difference in thermal stability of PNVF and PVAm polymers upon base hydrolysis was compared with thermal gravimetric analysis (TGA) and relevant TGA thermograms given in Fig. S3. The onset of the thermal degradation of PNVF polymer was observed between $199-236{ }^{\circ} \mathrm{C}$ with $31.9 \%$ weight loss and continued, and the second step between 250 and $615{ }^{\circ} \mathrm{C}$ with $95.2 \%$ weight loss and $4.8 \%$ residue was observed heating till $1000{ }^{\circ} \mathrm{C}$. On the other hand, three main thermal degradation stages were observed for PVAm. Briefly, in the first step of degradation, $5.5 \%$ weight loss was recorded between 80 and $150{ }^{\circ} \mathrm{C}$, while $60.7 \%$ cumulative weight loss was seen between 290 and $490{ }^{\circ} \mathrm{C}$ in the second degradation step. The third degradation step of PVAm has occurred between 640 and $675{ }^{\circ} \mathrm{C}$, reaching $72.1 \%$ weight loss which was slightly increased to 73.7 at $900{ }^{\circ} \mathrm{C}$ and $26.3 \%$ was the amount of residue.

\section{Synthesis of PVAm-based particles}

The schematic illustration of PVAm particle synthesis is illustrated in Fig. 1b along with corresponding digital camera images in dry and swollen states in Fig. 1c. The well-known Michael addition and epoxy-amine reactions were taken place in the synthesis of DVS and PEGGE crosslinked PVAm particles, respectively. Crosslinking of the amine groups of PVAm chains with the vinyl groups of DVS via Michaeltype addition reaction in basic conditions[26] gave rise to the formation of spherical PVAm-1 particles in cyclohexane/water medium in only $10 \mathrm{~min}$ at RT.

Amine compounds are known to easily react with epoxies, especially primary and secondary amines are highly reactive toward epoxide groups [31]. It is well accepted that epoxy reactions with amines follow the $\mathrm{SN}_{2}$ mechanism where the nucleophilic nitrogen atom attacks the carbon atom of the epoxy ring, and then, the hydrogen atom 
from the amine is eventually transferred to the epoxide oxygen to form $\mathrm{OH}$. Therefore, a primary amine can react two times with two epoxy groups, whereas a secondary amine can react only once. Tertiary amines do not react with epoxides, as their nucleophilicity is low. Therefore, PVAm chains with higher primary amine content in their structure crosslinked with epoxy groups of PEGGE in cyclohexane at $50{ }^{\circ} \mathrm{C}$. As seen from the optical microscope images of PVAm-1 and PVAm-2 particles in Fig. 1c, PVAm-1 particles with $2 \%$ crosslinker density were seemed to generate smaller sizes between 10 and $50 \mu \mathrm{m}$, whereas PVAm-2 particles with $5 \%$ crosslinker density gained much bigger sizes in the range of $20-150 \mu \mathrm{m}$ and in hydrated (swollen) forms make the particle much bigger almost twice of their dried. The difference in the sizes of PVAm-1 and PVAm-2 particles can be attributed to the different mixing rates of the corresponding precursors employed during synthesis (lower stirring rates result in general bigger particles) as well as the used amounts and the types of the crosslinkers as the crosslinking mechanism and rates can be different for unlike crosslinkers. Moreover, PVAm-2 particles were noticed to possess distorted spherical shapes yet spherical morphologies. The bigger particle formation of PVAm-2 as compared to PVAm-1 can be due to the longer chain length, elasticity, and the flexibility of epoxy groups group containing PEGGE crosslinker in comparison with DVS crosslinker. On the other hand, the use of different amounts of crosslinker of DVS and PEGGE to obtain PVAm particles can be explained with observed results. The increase in the amount of DVS resulted in the formation of PVAm gels instead of PVAm particles. With the increase in DVS amount, a crosslinked bulk gel was obtained instead of particles. Similarly, as lesser amounts of PEGGE were used, no particles were obtained. For this reason, 2\% DVS and 5\% PEGGE ratios, which are the minimum crosslinker ratios to attained spherical PVAm particles, were used.

The structural compositions of PVAm-1 and PVAm-2 particles were assessed by elemental analysis, and the elemental composition of the particles are given Table 1 . The percentage of crosslinking of PVAm-1 particles was calculated based on percentage of sulfur (S) element that directly comes from the crosslinker, DVS, and the percentage of nitrogen $(\mathrm{N})$ that is present in the PVAm-1. Hence, the percentage of crosslinking of PVAm-1 particles was found to be $11.8 \%$ by using Eq. 3 based on moles of DVS used in PVAm-1 particle. However, the crosslinking degree of PVAm-2 could not be calculated due to the lack of any distinguishable atom in PEGGE's structure.

$$
\% \text { Crosslinking }=x_{D V S} /\left(x_{D V S}+y_{P V A m-1}\right) \times 100
$$

where $x$ is the mole of DVS calculated by using $x=\mathrm{S} \% / 32.07$, and $y$ is the mole of PVAm- 1 calculated by using $y=\mathrm{N} \% / 14.01$.

SEM studies also reveal that PVAm-1 particles crosslinked with DVS maintain their spherical shape under vacuum and more rigid particles with fairly round

Table 1 Elemental analysis results of $f$ PVAm-1 and PVAm-2 particles

\begin{tabular}{lllcc}
\hline Sample & $\mathrm{C} \%$ & $\mathrm{H} \%$ & $\mathrm{~N} \%$ & $\mathrm{~S} \%$ \\
\hline PVAm-1 & 31.8 & 5.62 & 9.09 & 2.78 \\
PVAm-2 & 40.8 & 7.15 & 10.6 & - \\
\hline
\end{tabular}


sizes were attained as shown in Fig. 2a. On the other hand, PVAm-2 particles crosslinked with PEGGE resulted in bigger and flattened particles mostly appearing in agglomerated forms in their dry state, as revealed in Fig. 2b. The flexibility of PEGGE crosslinker due to the existence of ethylene oxide groups, pertinently makes PVAm-2 particles softer more elastic in comparison with DVS crosslinked PVAm-1 particle.

The surface charge is directly related to the surface properties of PVAm particles and its existence and the magnitude of zeta potential determines the potential use of PVAm particles in applications such as antibacterial materials or adsorbents. Therefore, the change in surface charges of PVAm-based DVS and PEGGE crosslinked particles was investigated between $\mathrm{pH} \mathrm{1-12,} \mathrm{and} \mathrm{the} \mathrm{corresponding} \mathrm{graph} \mathrm{is} \mathrm{shown}$
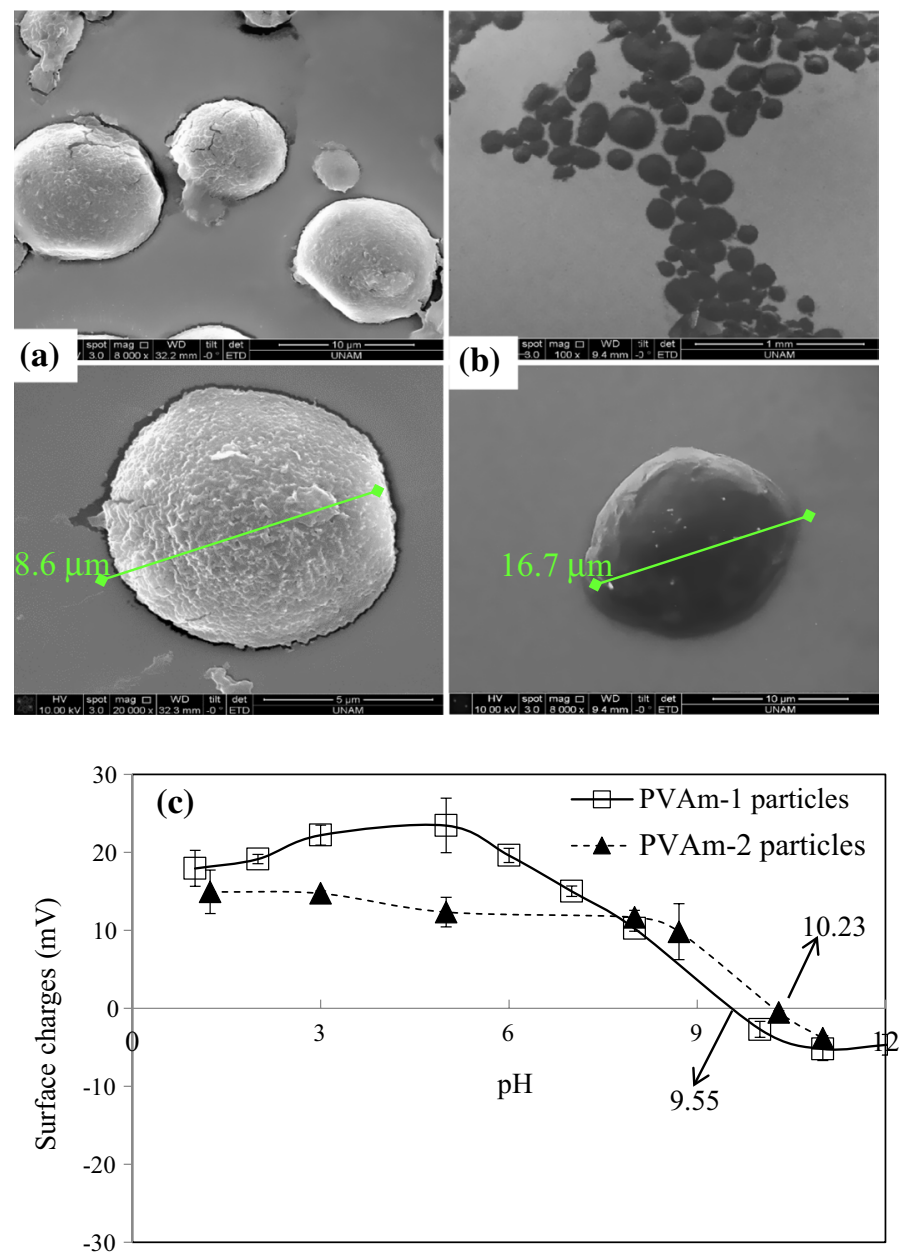

Fig. 2 SEM images of a PVAm-1, and b PVAm-2 particles, and $\mathbf{c}$ the change in surface charges of PVAm-based particles at various solution $\mathrm{pHs}$ 
in Fig. 2c. It was observed that both PVAm-1 and PVAm-2 particles were positively charged at all bodily fluid pHs, e.g., 1, 7.4 and around 8. Moreover, PVAm-1 particles were positively charged up to $\mathrm{pH} 9.5$, whereas PVAm-2 particles were positively charged up to $\mathrm{pH} 10.2$. Therefore, the isoelectronic points (IEP) of PVAm-1 and PVAm-2 particles were determined as $\mathrm{pH} 9.5$ and 10.2, respectively, state the fact that these particles are positively charged $<$ IEP of the corresponding particles rending them possible bacteriostatic and/or antibacterial properties.

The FT-IR spectra of PVAm-1 and PVAm-2 particles, their corresponding protonated forms, as well as linear PVAm polymers are compared in Fig. 3a. The N-H bending and $\mathrm{N}-\mathrm{H}$ stretching peaks were observed around 1600 and $3400 \mathrm{~cm}^{-1}$, respectively, for linear PVAm and they were also seen in PVAm-1 and PVAm-2 particles with slight shifts. For PVAm-1 particles, the $\mathrm{N}-\mathrm{H}$ bending peaks were observed at $1658 \mathrm{~cm}^{-1}$ and the characteristic peaks of DVS at 1123 and $1294 \mathrm{~cm}^{-1}$ due to $\mathrm{S}=\mathrm{O}$ stretching vibrations were present. For the PVAm-1-HCl particles, the
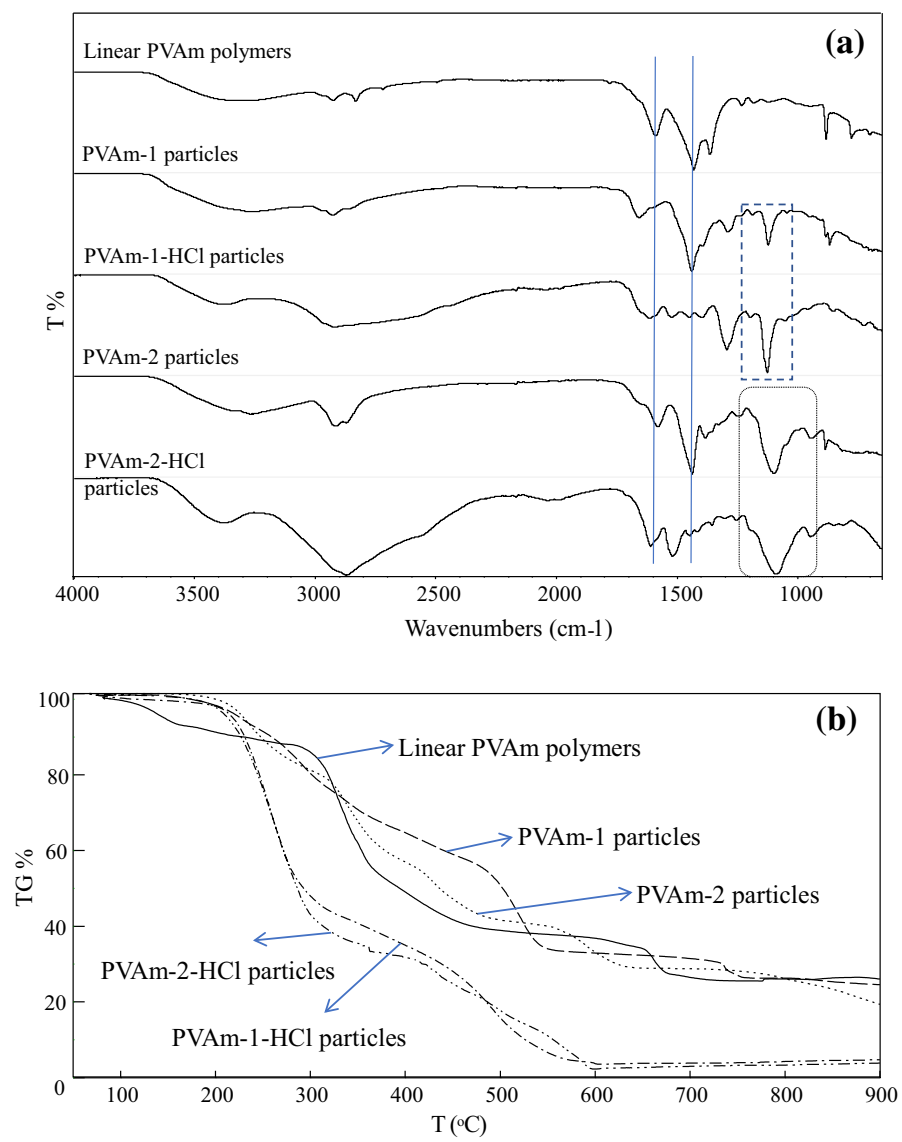

Fig. 3 a FT-IR spectra and b TGA thermograms of linear PVAm, PVAm particles, and their protonated forms 
$\mathrm{N}-\mathrm{H}$ stretching from protonated amine groups was observed at $1618 \mathrm{~cm}^{-1}$ together with characteristic peaks of DVS crosslinker [32]. Moreover, in FT-IR spectrum of PVAm-2 particles, the C-O stretching and $\mathrm{O}-\mathrm{H}$ bending from secondary alcohol groups due to PEGGE crosslinking of PVAm chains were observed at 1098 and $948 \mathrm{~cm}^{-1}$ [33], and the amine peaks shifted to $1608 \mathrm{~cm}^{-1}$ from $1582 \mathrm{~cm}^{-1}$ after protonation of PVAm-2 particles. The FT-IR analysis of the PVAm, PVAm particles, and their protonated forms clearly confirms incorporation of the DVS and PEGGE crosslinkers into PVAm chains directly proving the formation of crosslinked PVAm particles in one pot surfactant-free water-in-oil emulsion as it was also supported by the optical microscopy images.

The TGA thermograms of PVAm-1, PVAm-2 particles and their $\mathrm{HCl}$ treated forms are compared in Fig. $3 b$ to see the change in thermal stability after crosslinking and protonation of the prepared PVAm particles. The degradation profile of PVAM-1, PVAm-2, and their corresponding protonated forms were revealed some differences. It was observed that both PVAM-1 and PVAm-2 particles were shown three degradation steps, whereas their corresponding protonated forms showed 2 degradation steps. In addition, all PVAM-1, PVAM-2 and their corresponding protonated forms almost stable up to $180{ }^{\circ} \mathrm{C}$. Also, almost 75.4 and $80.4 \%$ weight losses were observed at $900{ }^{\circ} \mathrm{C}$ for PVAM-1 and PVAM-2 particles, whereas 95.3 and 96.3\% weight losses were observed $900{ }^{\circ} \mathrm{C}$ for PVAM-1.HCl and PVAM-2.HCl particles, respectively.

Thermal decomposition of PVAm polymers, PVAm-1, and PVAm-2 particles exhibited almost similar thermal degradation profiles. Likewise, PVAm-1-HCl and PVAm-2-HCl particles also shared similar decomposition patterns. As seen in Fig. 3b, the thermal stability of all PVAm-1, PVAm-2 particles are lower, whereas their corresponding protonated forms are higher than linear PVAm polymer suggesting that crosslinking of PVAm chains with DVS and PEGGE increased the thermal stability due to the covalent bonding of the polymer chains during the particle preparation process. On the other hand, the lower thermal stability of the protonated PVAm particles in comparison with neutral particle forms might be attributed to the instability coming from electrostatic repulsions among protonated amine groups, and also the generated amine salts may trigger different chain scission in polymer chains and changes in their distribution during the protonation process [34].

Moreover, it is reported that the amine group-containing polymer chains might exhibit fluorescent properties in cases where there are abundant number of amine groups on the polymer chains and the polymer has a linear structure rather than hyperbranched $[35,36]$.

A detailed study covering the tunable fluorescent properties of prepared PVAm chains from acidic and basic hydrolysis of PNVF chains was reported by our group [37]. Therefore, the excitation and emission spectra of linear PVAm, PVAm-1, and PVAm-2 particles prepared in this work were analyzed accordingly and given in Fig. 4. The maximum emission intensity of linear PVAm polymers was found to be at $378 \mathrm{~nm}$ with $310 \mathrm{~nm}$ of excitation wavelength at $700 \mathrm{~V}$ of PMT voltages. Likewise, the neutral and protonated PVAm-1 and PVAm-2 particles have exhibited excitation and emission peaks. As shown in Fig. 4a, the maximum emission intensity of PVAm-1 particles appeared at $377 \mathrm{~nm}$ with $310 \mathrm{~nm}$ of excitation wavelength, while 

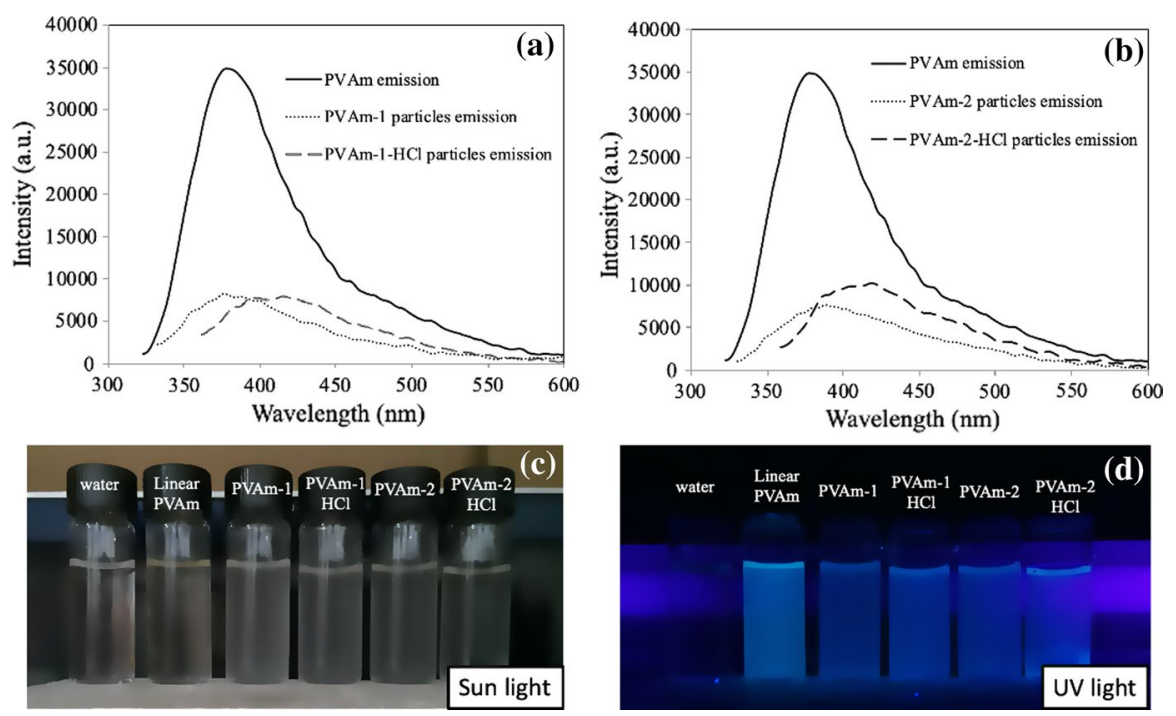

Fig. 4 Fluorescent properties of a neutral and protonated PVAm-1, and b PVAm-2 particles with linear PVAm polymers, and $\mathbf{c}$ their digital camera images under daylight, and d UV light at $366 \mathrm{~nm}$

for the PVAm-1-HCl particles, maximum emission and excitation wavelengths were redshifted to $416 \mathrm{~nm}$ and $336 \mathrm{~nm}$, respectively, at the same PMT voltages.

The excitation and emission spectra of linear PVAm, neutral, and protonated PVAm-2 particles are plotted in Fig. 4b. The maximum emission intensity peaks of PVAm-2 particles were recorded at $389 \mathrm{~nm}$ with the excitation of $310 \mathrm{~nm}$ at $700 \mathrm{~V}$ of PMT that showed shift upon protonation and exhibited emission at $419 \mathrm{~nm}$ upon excitation at $340 \mathrm{~nm}$. Linear PVAm, PVAm-1, PVAm-2 particles, and their respective protonated forms were visualized under daylight and UV light at $366 \mathrm{~nm}$, and their digital camera images are provided in Fig. 4b, c, respectively.

This behavior that the fluorescent intensity of linear PVAm was decreased after crosslinking of the polymer chains is in good agreement with the observations in literature $[35,36]$. Upon crosslinking both the number of free amine groups and linearity of the PVAm polymers were decreased with the incorporation of the crosslinkers into the polymer structure. Moreover, the emission and excitation wavelengths of PVAm particles as well as their protonated forms were acquired significant redshifts (increase in wavelengths) as compared to linear PVAm and behaved in between the neutral and protonated particle forms. Also, it has been reported that the increase in the chain length decreases the fluorescence intensity due to the quenching effect of longer chains [38]. Therefore, the difference in chain lengths between DVS and PEGGE used as crosslinkers may affect the molecular intra-chain mobility of PVAm-based particles and cause a decrease in fluorescence intensity after particle preparation. In addition, the redshift observed in the UV and fluorescence spectrum of PVAm-1 and PVAm-2 particles after protonation can be explained by the enhanced charge transfer character of PVAm-1.HCl and PVAm-2.HCl upon protonation [39]. The difference in the molecular structure of DVS and PEGGE and 
their size also can contribute different to the flurosnecen properties of PVAm-1 and PVAm-2 particles. Consequently, both of the protonated PVAm particles attained relatively higher intensities with respect to neutral PVAm particles as obviously apparent in fluorescence spectra and digital camera images of the particles.

\section{Degradation of PVAm particles}

The hydrolytic degradation kinetics of crosslinked structures is known to depend on several factors such as $\mathrm{pH}$, temperature, type, and density of crosslinker used and can be finely tuned by controlling these parameters [40]. Therefore, the in vitro hydrolytic degradation of PVAm-1 and PVAm-2 particles at $\mathrm{pH} 5.4, \mathrm{pH} \mathrm{7.4}$, and $\mathrm{pH} 9.0$ was investigated at $37^{\circ} \mathrm{C}$ by monitoring the amount of degraded PVAm by means of UV-Vis spectroscopy, and the corresponding results are demonstrated in Fig. 5a, b, respectively. While PVAm-1 and PVAm-2 particles were found to be stable up to $80 \mathrm{~h}$ at $\mathrm{pH} 5.4$, a linear degradation profile had been observed for both
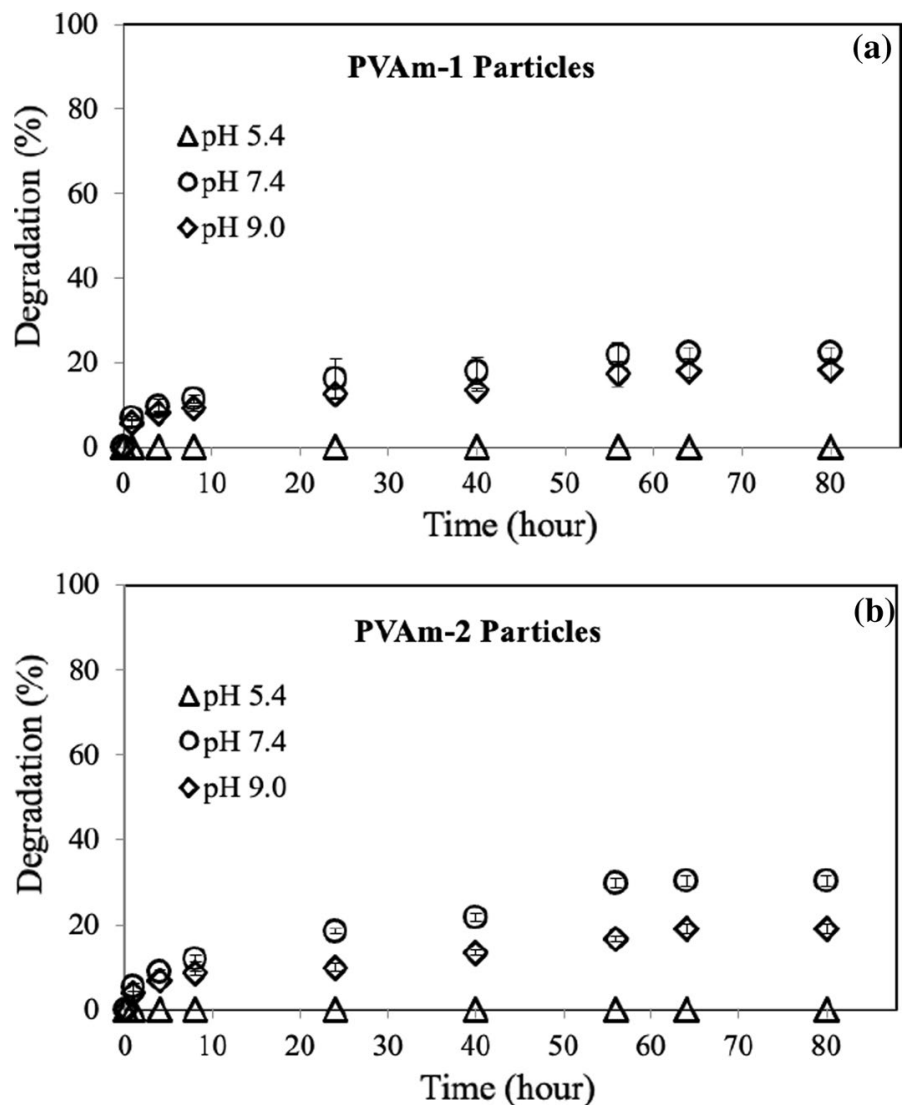

Fig. 5 Hydrolytic degradation profiles of a PVAM-1 and b PVAm-2 particles at different pHs 
particles at pH 7.4 and 9.0 up to $56 \mathrm{~h}$. Then, hydrolytic degradation has shown to be progressed at a slower pace up to $80 \mathrm{~h}$.

Hydrolytically PVAm-1 particles exhibited $21.8 \pm 2.9 \%$ weight loss in $56 \mathrm{~h}$ and ended up with total of $22.3 \pm 1.4 \%$ weight loss at $\mathrm{pH} 7.4$ in $80 \mathrm{~h}$. Similarly, at pH 9, PVAm-1 particles showed $17.4 \pm 2.9 \%$ and $18.3 \pm 2.1 \%$ weight loss in the specified time periods. In the same way, PVAm-2 particles were found to be stable for $80 \mathrm{~h}$ at $\mathrm{pH} 5.4$ with no significant degradation. On the other hand, at $\mathrm{pH} 7.4$ and 9.0, PVAm-2 particles displayed $29.9 \pm 0.9 \%$ and $16.6 \pm 0.7 \%$ weight losses in $56 \mathrm{~h}$, respectively, and continued to degrade slowly up to $80 \mathrm{~h}$ with final weight losses of $30.3 \pm 1.0 \%$ and $19.2 \pm 1.2 \%$, respectively. The stability of PVAm-1 and PVAm-2 particles at pH 5.4 can be explained with the higher inter- and intra-hydrogen bonding capabilities of PVAm chains, as the protonated amine groups can readily and more strongly interact with the unprotonated amine groups and with the crosslinkers in comparison with unprotonated or lesser protonated amine groups. On the other hand, the higher degradation \% of both PVAm-1 and PVAm-2 particles at $\mathrm{pH} 7.4$ than $\mathrm{pH} 9.0$ can be attributed to the greater swelling ability of cationic polymers at lower $\mathrm{pH}$ values [41].

Consequently, it can be inferred from the degradation data that both PVAm-1 and PVAm-2 particles are stable in acidic conditions but more susceptible to degradation in neutral rather than basic conditions. PVAm-2 particles degrade more than PVAm-1 particles in both neutral and basic conditions. So, it can be assumed that although DSV and PEGGE have different chemical structures, they both resulted in the similar degradation pattern at the same $\mathrm{pH}$ conditions.

\section{Blood compatibility of PVAm particles}

Blood compatibility is an essential prerequisite for in vivo applications of micro/ nanomaterials such as drug delivery, gene therapy, wound dressing and so on [42]. Polyelectrolyte cations are known to interact with the lipid membranes of cells and due to their high charge density and induce hemolysis in red blood cells (RBCs) [43-46]. In vitro haemocompatibility of neutral and protonated PVAm particles was evaluated at $0.01,0.1$, and $1 \mathrm{mg} / \mathrm{mL}$ concentrations by measuring their hemolytic and blood clotting behaviors, and the respective graphs are given in Fig. 6a, b, respectively. Neutral and protonated PVAm particles were found to induce hemolysis on RBCs in a concentration-dependent manner. At the highest applied concentration of $1.0 \mathrm{mg} / \mathrm{mL}$, PVAm-1 and PVAm-2 particles caused $68.0 \pm 8.5 \%$ and $53.0 \pm 1.3 \%$ hemolysis, whereas PVAm-1-HCl and PVAm-2-HCl particles exhibited $58.9 \pm 1.1 \%$ and $61.7 \pm 0.5 \%$ hemolysis, respectively. At this concentration $(1.0 \mathrm{mg} /$ $\mathrm{mL}$ ), neutral and protonated PVAm particles were found to be detrimental to RBCs. On the other hand, the hemolysis induction of both neutral and protonated PVAm particles at 0.1 and $0.01 \mathrm{mg} / \mathrm{mL}$ concentrations was found to fall into clinical safety margins with less than 5\% hemolysis. Accordingly, PVAm-1 and PVAm-2 particles with $1.0 \pm 0.1 \%$ and $1.6 \pm 0.1 \%$ hemolysis ratios were obtained at $0.1 \mathrm{mg} / \mathrm{mL}$ particle concentration and at $0.01 \mathrm{mg} / \mathrm{mL}$ particle concentration, they were found to induce $0.1 \pm 0.1 \%$ and $1.0 \pm 0.1 \%$ hemolysis, respectively. As the concentration of 


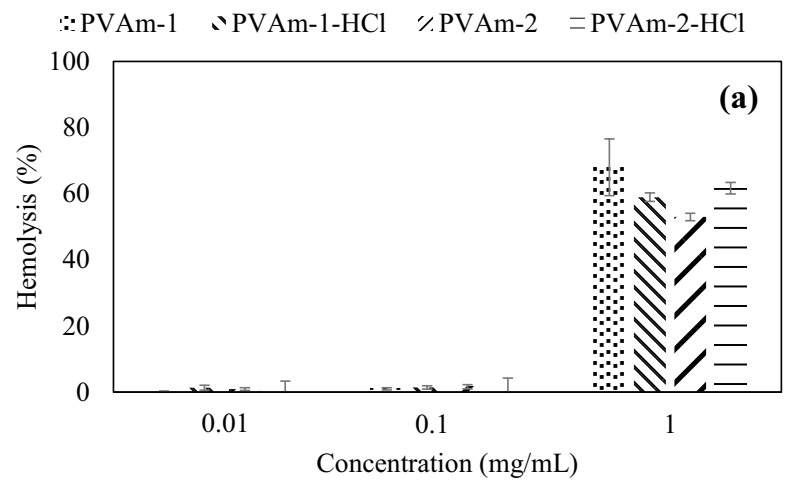

:: PVAm-1 NPVAm-1-HCl $\because \mathrm{PVAm}-2 \quad \equiv \mathrm{PVAm}-2-\mathrm{HCl}$

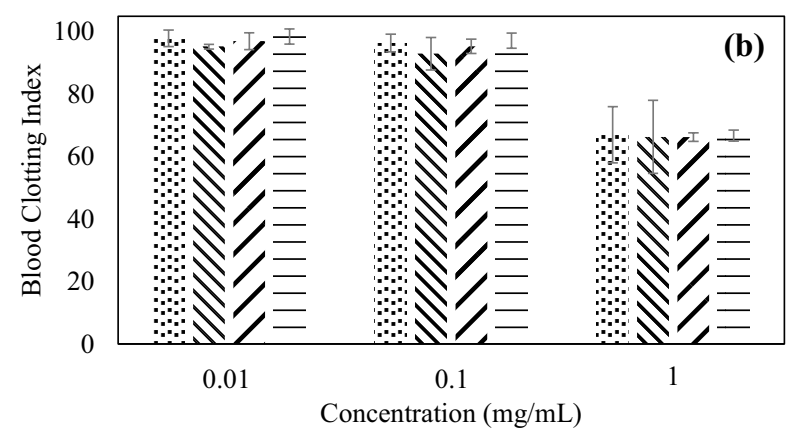

Fig. 6 Assessment of in vitro a hemolysis and $\mathbf{b}$ blood clotting behaviors of neutral and protonated PVAm particles at $0.01,0.1$, and $1 \mathrm{mg} / \mathrm{mL}$ concentrations

PVAM-1-HCl and PVAm-2-HCl particles increased from $0.01 \mathrm{mg} / \mathrm{mL}$ to $0.1 \mathrm{mg} /$ $\mathrm{mL}$, the hemolysis \% values of $1.4 \pm 0.1 \%$ and $1.9 \pm 0.2 \%$, respectively, were changed to $1.4 \pm 0.1 \%$ and $0.9 \pm 0.2 \%$. Accordingly, for the PVAm-1 and PVAm-2 particles and their protonated forms can be used at $>0.1 \mathrm{mg} / \mathrm{mL}$ in blood contacting applications.

Blood clotting index is another means of compatibility evaluation on particleblood interactions. Basically the degree of clotting was quantified by measuring the extent of hemoglobin content of RBCs that was captured during the course of clot formation [26]. Test samples were assessed using a blood control that contains only blood solution in water, and clotting activity of samples was interpreted according to reference blood. PVAm particles were observed to exert slightly coagulative effects at $1.0 \mathrm{mg} / \mathrm{mL}$ concentration upon interaction with the whole blood. PVAm-1 PVAm-2 particles and their protonated forms, respectively, resulted in $67.0 \pm 9.0 \%$, $66.3 \pm 1.3 \%, 66.3 \pm 11.7 \%$, and $66.8 \pm 1.7 \%$ blood clotting indices in comparison with reference blood control. On the other hand, at $0.1 \mathrm{mg} / \mathrm{mL}$ concentrations of PVAm-1 and PVAm-2 particles and their protonated forms showed, respectively, 
$96.4 \pm 4.5 \%, 95.4 \pm 1.5 \%, 93.0 \pm 0.5 \%$, and $97.2 \pm 1.3 \%$ blood clotting indices, whereas at $0.01 \mathrm{mg} / \mathrm{mL}$ concentrations, $97.9 \pm 9.0 \%, 97.0 \pm 1.0 \%, 95.2 \pm 4.0 \%$, and $98.5 \pm 1.0 \%$ blood clotting indices were calculated, respectively. The process of blood coagulation is a complex mechanism regulated by intrinsic and extrinsic pathways. In order to determine the mode of action for PVAm-based particles, more specific assays should be performed to estimate proper dosing schemes for in vivo applications. Consequently, PVAm-based particles were found to be compatible to blood up to $0.1 \mathrm{mg} / \mathrm{mL}$ concentrations. The increase in particle concentration, e.g., to $1.0 \mathrm{mg} / \mathrm{mL}$ caused highly hemolytic and slightly coagulative effects as revealed by in vitro hemolysis and blood clotting assays. It should be also be noted that in addition to the use of suitable particle concentration range, the haemocompatibility of micro/nano assemblies and particles can also be tuned by the introduction of biocompatible molecules such as carbohydrate moieties to lower the toxicity induced by carrier materials $[45,47]$.

\section{Antimicrobial activity assessment}

To determine antifungal and antibacterial efficacy of PVAm-based particles, $C$. albicans yeast and E. coli, S. aureus, B. subtilis, and P. aeruginosa bacterial strains were exploited as the model organisms substantially used in laboratory assessment of antimicrobial activity. Minimum inhibitory concentration (MIC) is described as the lowest concentration of particles that bacterial growth media exhibiting clear appearance such as turbidity of the present bacteria cannot be distinguished with naked eyes. Minimum bactericidal concentration (MBC) on the other hand is the lowest concentration of an antimicrobial agent that prevent visible growth of bacteria in both specified period of incubation time and after subculturing of the inoculum, exerting 99\% killing efficiency. The MIC score of antimicrobial materials is of significant importance; hence, it is mostly used as a complementary indication to MBC and helps to adjust the proper dosing schemes in the treatment of pervasive microbial infections [48]. Polyelectrolytes of amine polymers are known to possess a broad spectrum of antibacterial efficiency depending on the charge density and hydrophobicity of the chosen polymers [45, 46, 49]. PVAm particles and their protonated forms were tested against the aforementioned microbial organisms and the MIC and MBC scores of the tested particles are summarized in Table 2. PVAm-1$\mathrm{HCl}$ and $\mathrm{PVAm}-2-\mathrm{HCl}$ have performed expectedly higher antibacterial and antifungal efficiency in comparison with neutral PVAm particles. The MBC score of all the samples was determined to be $10 \mathrm{mg} / \mathrm{mL}$ for all the bacteria and yeast cultures, excepting neutral PVAm-1 and PVAm-2 against C. albicans that possessed minimum fungicidal concentration (MFC) of $20 \mathrm{mg} / \mathrm{mL}$.

The MIC scores of PVAm-1-HCl and PVAm-2-HCl particles were $2.5 \mathrm{mg} / \mathrm{mL}$ for all bacteria and yeast strains. MIC values of gentamycin as a model antibiotic drug for $C$. albicans yeast strain and E. coli, B. subtilis, S. aureus for $P$. aeruginosa bacteria were reported to be $0.0025 \mathrm{mg} / \mathrm{mL}, 0.008 \mathrm{mg} / \mathrm{mL}, 0.004 \mathrm{mg} / \mathrm{mL}, 0.01 \mathrm{mg} / \mathrm{mL}$, and $0.004 \mathrm{mg} / \mathrm{mL}$, respectively [50-54]. Compared to PVAm-1-HCl and PVAm2-HCl, PVAm-1 and PVAm-2 had higher MIC values against bacterial and fungal 
Table $2 \mathrm{MIC}$ and $\mathrm{MBC}$ values of PVAm $\mathrm{HCl}$ as a polymer and PVAm-based particles against E. coli (gram -) S. aureus (gram+), B. subtilis (gram+) and P. aeruginosa (gram -) as bacteria and C. albicans as fungi strain

\begin{tabular}{|c|c|c|c|c|c|c|c|c|c|c|}
\hline \multirow{2}{*}{$\begin{array}{l}\text { Particles } \\
\text { Organisms }\end{array}$} & \multicolumn{2}{|c|}{ PVAm HCl } & \multicolumn{2}{|c|}{ PVAm-1 } & \multicolumn{2}{|c|}{ PVAm-1-HCl } & \multicolumn{2}{|c|}{ PVAm-2 } & \multicolumn{2}{|c|}{ PVAm-2-HCl } \\
\hline & MIC & $\mathrm{MBC}$ & MIC & MBC & MIC & $\mathrm{MBC}$ & MIC & MBC & MIC & MBC \\
\hline E. coli & 0.25 & 0.5 & 5 & 10 & 2.5 & 10 & 5 & 10 & 2.5 & 10 \\
\hline P. aeruginosa & 0.25 & 0.5 & 5 & 10 & 2.5 & 10 & 10 & 10 & 2.5 & 10 \\
\hline S. aureus & 0.25 & 0.5 & 5 & 10 & 2.5 & 10 & 5 & 10 & 2.5 & 10 \\
\hline B. subtilis & 0.25 & 0.5 & 5 & 10 & 2.5 & 10 & 5 & 10 & 2.5 & 10 \\
\hline C. albicans & 0.25 & 0.5 & 10 & 20 & 2.5 & 10 & 10 & 20 & 2.5 & 10 \\
\hline
\end{tabular}

*All concentrations for MIC and MBC are $\mathrm{mg} / \mathrm{mL}$

strains. The higher MIC value refers to the higher concentration of a material that is required to be effectively used as an antimicrobial agent. Protonation caused elevation in the antimicrobial efficacy of particles as it increased the cationic charge density on the particle surface. PVAm-HCl polymer possessed the lowest values for both $\mathrm{MBC}$ as $0.5 \mathrm{mg} / \mathrm{mL}$ and $\mathrm{MIC}$ as $0.25 \mathrm{mg} / \mathrm{mL}$ with respect to antimicrobial activity on the five mentioned cultures. The linear polymer form is much more effective as compared to the particle forms of PVAm in terms of antimicrobial and antifungal efficacy owing to the fact that they are more flexible and have higher degrees of freedom (multiple contact points) to interact with the microorganisms enabling a linear polymer to destroy the membrane of both bacterial and fungal organisms more easily. As it is reported, the increased surface area is more effective for antibacterial studies [55]. Thus, contact area of a loose and flexible polymer was found more effectual in comparison with the particles owing to surface area of free polymer chains is much than the particles. On the other hand, the particle can still damage the membrane of microorganisms, with higher initial concentrations. Additionally, PVAm polymer and oligomers are expected to form when the particles degrade as elaborated before leading to long term antimicrobial effect of PVAm particles. Furthermore, antimicrobial activity of PVAm particles can be further increased either by adjusting the hydrophobicity through chemical modifications, e.g., substitutions with quaternary ammonium compounds of varying alkyl chains, or by increasing the molecular weight of PVAm polymers via adjusting the degree of polymerization of precursor PNVF polymers [45, 46, 56].

\section{Conclusions}

DVS and PEGGE crosslinked PVAm-based particles with highly flexible 3D morphology and low crosslinking density were synthesized in a surfactant-free waterin-oil emulsion system. PVAm particles and their protonated forms were revealed to possess fluorescent properties, although the intensity of the particle forms was lower than the linear precursors. 3D network morphology imparted by crosslinking can provide a useful basis for imaging applications and fluorescent properties of the 
particles can be enhanced by entrapment/conjugation of contrast agents as well as carrier for different active agents. Both formulations of PVAm particles were hydrolytically degraded in physiological $\mathrm{pH}$ environments and lost $20-30 \%$ of their weight depending of medium pHs. All forms of PVAm particles were found to be compatible to blood interactions depending on concentration of particles at $<0.1 \mathrm{mg} / \mathrm{mL}$ particle concentration. Furthermore, PVAm particles especially the protonated form showed bacteriostatic properties which is very important in the prevention of bacterial infections making them useful for such applications against common yeast, gram-positive and gram-negative bacterial strains. Moreover, the availability of the abundant numbers of amine groups in PVAm particles make them versatile tools to be coupled with innocuous molecules or biopolymers to deliver enhanced biological applications rendering higher biocompatibility (lower toxicity), antioxidant and antibactericidal activity, bioimaging, drug delivery, and so on. The amine functionality of PVAm networks makes them highly versatile and multifunctional alternatives toward a broad spectrum of applications include wastewater treatment, antimicrobial coatings on medical devices, surfaces, or hygiene products.

Supplementary Information The online version contains supplementary material available at https://doi. org/10.1007/s00289-021-03874-9.

\section{References}

1. Yamamoto K, Imamura Y, Nagatomo E et al (2003) Synthesis and functionalities of poly(Nvinylalkylamide). XIV. Polyvinylamine produced by hydrolysis of poly(N-vinylformamide) and its functionalization. J Appl Polym Sci 89:1277-1283. https://doi.org/10.1002/app.12230

2. Pinschmidt RK (2010) Polyvinylamine at last. J Polym Sci Part A Polym Chem 48:2257-2283. https://doi.org/10.1002/pola.23992

3. Martel B, Morcellet M (1995) Cyclodextrin-poly(vinylamine) systems-II Catalytic hydrolysis of p-nitrophenyl acetate. Eur Polym J 31:1089-1093

4. Illergård J, Römling U, Wågberg L, Ek M (2012) Biointeractive antibacterial fibres using polyelectrolyte multilayer modification. Cellulose 19:1731-1741. https://doi.org/10.1007/ s10570-012-9742-0

5. Seifert S, Simon F, Baumann G et al (2011) Adsorption of poly(vinyl formamide- co -vinyl amine) (PVFA-co-PVAm) polymers on zinc, zinc oxide, iron, and iron oxide surfaces. Langmuir 27:14279-14289. https://doi.org/10.1021/la203479n

6. Hollertz R, Durán VL, Larsson PA, Wågberg L (2017) Chemically modified cellulose microand nanofibrils as paper-strength additives. Cellulose 24:3883-3899. https://doi.org/10.1007/ s10570-017-1387-6

7. Huang Y, Du J, Zhang Y et al (2016) Batch process of polymer-enhanced ultrafiltration to recover mercury (II) from wastewater. J Memb Sci 514:229-240. https://doi.org/10.1016/j.memsci.2016.04.060

8. Casadei R, Venturi D, Baschetti MG et al (2019) Polyvinylamine membranes containing graphene-based nanofillers for carbon capture applications. Membranes (Basel) 9:119. https://doi. org/10.3390/membranes9090119

9. Dréan M, Debuigne A, Goncalves C et al (2017) Use of Primary and Secondary Polyvinylamines for Efficient Gene Transfection. Biomacromol 18:440-451. https://doi.org/10.1021/acs.biomac. $6 \mathrm{~b} 01526$

10. Khondee S, Yakovleva T, Berkland C (2010) Low charge polyvinylamine nanogels offer sustained, low-level gene expression. J Appl Polym Sci 118:1921-1932. https://doi.org/10.1002/ app. 32460 
11. Chen Y, Sun P (2019) pH-Sensitive Polyampholyte Microgels of Poly(Acrylic Acid-co-Vinylamine) as Injectable Hydrogel for Controlled Drug Release. Polymers (Basel) 11:285. https://doi.org/10. 3390/polym11020285

12. Henschen $\mathbf{J}$, Larsson PA, Illergård $\mathbf{J}$ et al (2017) Bacterial adhesion to polyvinylamine-modified nanocellulose films. Colloids Surfaces B Biointerfaces 151:224-231. https://doi.org/10.1016/j.colsu rfb.2016.12.018

13. Chen $\mathrm{C}$, Petterson T, Illergård $\mathbf{J}$ et al (2019) Influence of Cellulose Charge on Bacteria Adhesion and Viability to PVAm/CNF/PVAm-Modified Cellulose Model Surfaces. Biomacromol 20:20752083. https://doi.org/10.1021/acs.biomac.9b00297

14. Marini M, Bondi M, Iseppi R et al (2007) Preparation and antibacterial activity of hybrid materials containing quaternary ammonium salts via sol-gel process. Eur Polym J 43:3621-3628

15. Yang Y, Cai Z, Huang Z et al (2018) Antimicrobial cationic polymers: From structural design to functional control. Polym J 50:33-44. https://doi.org/10.1038/pj.2017.72

16. Palermo EF, Kuroda K (2009) Chemical structure of cationic groups in amphiphilic polymethacrylates modulates the antimicrobial and hemolytic activities. Biomacromol 10:1416-1428. https:// doi.org/10.1021/bm900044x

17. Chen Z, Lv Z, Sun Y et al (2020) Recent advancements in polyethyleneimine-based materials and their biomedical, biotechnology, and biomaterial applications. J Mater Chem B 8:2951-2973. https://doi.org/10.1039/c9tb02271f

18. Thaiboonrod S, Berkland C, Milani AH et al (2013) Poly(vinylamine) microgels: PH-responsive particles with high primary amine contents. Soft Matter 9:3920-3930. https://doi.org/10.1039/ c3sm27728c

19. Thaiboonrod S, Milani AH, Saunders BR (2014) Doubly crosslinked poly(vinyl amine) microgels: Hydrogels of covalently inter-linked cationic microgel particles. J Mater Chem B 2:110-119. https:// doi.org/10.1039/c3tb21579b

20. McCann J, Behrendt JM, Yan J et al (2015) Poly(vinylamine) microgel-dextran composite hydrogels: Characterisation; properties and pH-triggered degradation. J Colloid Interface Sci 449:21-30. https://doi.org/10.1016/j.jcis.2014.09.041

21. Shi L, Berkland C (2007) Acid-labile polyvinylamine micro- and nanogel capsules. Macromolecules 40:4635-4643. https://doi.org/10.1021/ma070443o

22. Bonnefond A, Pereira Gomes C, de la Cal JC, Leiza JR (2017) Surfactant-free poly(methyl methacrylate)/poly(vinylamine) (PMMA/PVAm) amphiphilic core-shell polymer particles. Colloid Polym Sci 295:135-144. https://doi.org/10.1007/s00396-016-3985-5

23. Gu L, Zhu S, Hrymak AN, Pelton RH (2001) Kinetics and modeling of free radical polymerization of N-vinylformamide. Polymer (Guildf) 42:3077-3086. https://doi.org/10.1016/S0032-3861(00) 00654-6

24. Gu L, Zhu S, Hrymak AN (2002) Acidic and basic hydrolysis of poly(N-vinylformamide). J Appl Polym Sci 86:3412-3419. https://doi.org/10.1002/app.11364

25. Horikoshi S, Akao Y, Ogura T et al (2010) On the stability of surfactant-free water-in-oil emulsions and synthesis of hollow SiO2 nanospheres. Colloids Surfaces A Physicochem Eng Asp 372:55-60. https://doi.org/10.1016/j.colsurfa.2010.09.036

26. Can M, Ayyala RS, Sahiner N (2019) Crosslinked poly(Lactose) microgels and nanogels for biomedical applications. J Colloid Interface Sci 553:805-812. https://doi.org/10.1016/j.jcis.2019.06. 078

27. Reynolds DD, Kenyon WO (1947) The Preparation of Polyvinylamine, Polyvinylamine Salts, and Related Nitrogenous Resins

28. Dawson DJ, Gless RD, Wingard RE (1976) Poly(vinylamine hydrochloride). Synthesis and Utilization for the Preparation of Water-Soluble Polymeric Dyes. J Am Chem Soc 98:5996-6000. https:// doi.org/10.1021/ja00435a036

29. Tanaka H, Senju R (1976) Preparation of polyvinylamine by the Hoffmann degradation of polyacrylamide. Bull Chem Soc Jpn 49:2821-2823

30. Yatabe R, Onodera T, Toko K (2013) Highly sensitive detection of 2,4,6-trinitrotoluene(TNT) using poly(vinylamine-co-N-vinylformamide)based surface plasmon resonance (SPR) immunosensor. Sensors Mater 25:45-56

31. Pham HQ, Marks MJ (2005) Epoxy Resins. In: Ullmann's Encyclopedia of Industrial Chemistry. Wiley-VCH Verlag GmbH \& Co. KGaA, Weinheim, Germany

32. Demirci S, Sahiner N (2014) PEI-based ionic liquid colloids for versatile use: Biomedical and environmental applications. J Mol Liq 194:85-92. https://doi.org/10.1016/j.molliq.2014.01.015 
33. Sahiner N, Demirci S (2016) Poly ionic liquid cryogel of polyethyleneimine: Synthesis, characterization, and testing in absorption studies. J Appl Polym Sci. https://doi.org/10.1002/app.43478

34. Pei Y, Zhao L, Du G et al (2016) Investigation of the degradation and stability of acrylamide-based polymers in acid solution: Functional monomer modified polyacrylamide. Petroleum 2:399-407. https://doi.org/10.1016/j.petlm.2016.08.006

35. Chen Y, Zhang Y (2011) Fluorescent quantification of amino groups on silica nanoparticle surfaces. Anal Bioanal Chem 399:2503-2509. https://doi.org/10.1007/s00216-010-4622-7

36. Pastor-Pérez L, Chen Y, Shen Z et al (2007) Unprecedented blue intrinsic photoluminescence from hyperbranched and linear polyethylenimines: Polymer architectures and pH-effects. Macromol Rapid Commun 28:1404-1409. https://doi.org/10.1002/marc.200700190

37. Sütekin SD, Demirci S, Kurt SB et al (2021) Tunable fluorescent and antimicrobial properties of poly(vinyl amine) affected by the acidic or basic hydrolysis of poly(N-vinylformamide). J Appl Polym Sci 51234:1-16. https://doi.org/10.1002/app.51234

38. Bazan GC, Miao YJ, Renak ML, Sun BJ (1996) Fluorescence quantum yield of oly(p-phenylenevinylene) prepared via the paracyclophene route: Effect of chain length and interchain contacts. J Am Chem Soc 118:2618-2624. https://doi.org/10.1021/ja953716g

39. Maity S, Shyamal M, Das D et al (2018) Proton triggered emission and selective sensing of 2,4,6-trinitrophenol using a fluorescent hydrosol of 2-phenylquinoline. New J Chem 42:1879-1891. https://doi.org/10.1039/c7nj03861e

40. Sailema-Palate GP, Vidaurre A, Campillo-Fernández AJ, Castilla-Cortázar I (2016) A comparative study on Poly( $\varepsilon$-caprolactone) film degradation at extreme pH values. Polym Degrad Stab 130:118125. https://doi.org/10.1016/j.polymdegradstab.2016.06.005

41. Drozdov AD, Declaville Christiansen J (2015) Modeling the effects of $\mathrm{pH}$ and ionic strength on swelling of polyelectrolyte gels. J Chem Phys. https://doi.org/10.1063/1.4914924

42. de la Harpe KM, Kondiah PPD, Choonara YE et al (2019) The Hemocompatibility of Nanoparticles: A Review of Cell-Nanoparticle Interactions and Hemostasis. Cells 8:1209. https://doi.org/10. 3390/cells8101209

43. Klajnert B, Pikala S, Bryszewska M (2010) Haemolytic activity of polyamidoamine dendrimers and the protective role of human serum albumin. Proc R Soc A Math Phys Eng Sci 466:1527-1534. https://doi.org/10.1098/rspa.2009.0050

44. Palermo EF, Sovadinova I, Kuroda K (2009) Structural Determinants of Antimicrobial Activity and Biocompatibility in Membrane-Disrupting Methacrylamide Random Copolymers. Biomacromol 10:3098-3107. https://doi.org/10.1021/bm900784x

45. Ilker MF, Nüsslein K, Tew GN, Coughlin EB (2004) Tuning the Hemolytic and Antibacterial Activities of Amphiphilic Polynorbornene Derivatives. J Am Chem Soc 126:15870-15875. https://doi. org/10.1021/ja045664d

46. Carmona-Ribeiro A, de Melo CL (2013) Cationic Antimicrobial Polymers and Their Assemblies. Int J Mol Sci 14:9906-9946. https://doi.org/10.3390/ijms14059906

47. Kennedy DC, Orts-Gil G, Lai C-H et al (2014) Carbohydrate functionalization of silver nanoparticles modulates cytotoxicity and cellular uptake. J Nanobiotechnology 12:59. https://doi.org/10. 1186/s12951-014-0059-z

48. Leigue L, Montiani-Ferreira F, Moore BA (2016) Antimicrobial susceptibility and minimal inhibitory concentration of Pseudomonas aeruginosa isolated from septic ocular surface disease in different animal species. Open Vet J 6:215. https://doi.org/10.4314/ovj.v6i3.9

49. Palermo EF, Lee D-K, Ramamoorthy A, Kuroda K (2011) Role of Cationic Group Structure in Membrane Binding and Disruption by Amphiphilic Copolymers. J Phys Chem B 115:366-375. https://doi.org/10.1021/jp1083357

50. Helmy S, Mohamed SS, Mahmoud SS, Talaat M (2015) Preparation and Characterization of DMPC Liposomal-Gentamicin; Antibacterial Time-Kill Study on Escherichia coli ATCC 8739. Int J Innov Sci Eng Technol 3:221-224

51. Leite AM, Lima EDO, De Souza EL et al (2007) Inhibitory effect of $\beta$-pinene, $\alpha$-pinene and eugenol on the growth of potential infectious endocarditis causing Gram-positive bacteria. Rev Bras Ciencias Farm J Pharm Sci 43:121-126. https://doi.org/10.1590/S1516-93322007000100015

52. Lu M, Yu C, Cui X et al (2018) Gentamicin synergises with azoles against drug-resistant Candida albicans. Int J Antimicrob Agents 51:107-114. https://doi.org/10.1016/j.ijantimicag.2017.09.012

53. Adimpong DB, Sørensen KI, Thorsen L et al (2012) Antimicrobial susceptibility of bacillus strains isolated from primary starters for african traditional bread production and characterization of the 
bacitracin operon and bacitracin biosynthesis. Appl Environ Microbiol 78:7903-7914. https://doi. org/10.1128/AEM.00730-12

54. Machado I, Graça J, Lopes H et al (2013) Antimicrobial Pressure of Ciprofloxacin and Gentamicin on Biofilm Development by an Endoscope-Isolated Pseudomonas aeruginosa. ISRN Biotechnol 2013:1-10. https://doi.org/10.5402/2013/178646

55. Yamamoto $O$ (2001) Influence of particle size on the antibacterial activity of zinc oxide. Int J Inorg Mater 3:643-646. https://doi.org/10.1016/S1466-6049(01)00197-0

56. Westman E-H, Ek M, Enarsson L-E, Wågberg L (2009) Assessment of Antibacterial Properties of Polyvinylamine (PVAm) with Different Charge Densities and Hydrophobic Modifications. Biomacromol 10:1478-1483. https://doi.org/10.1021/bm900088r

Publisher's Note Springer Nature remains neutral with regard to jurisdictional claims in published maps and institutional affiliations.

\section{Authors and Affiliations}

\section{Sahin Demirci ${ }^{1,2} \cdot$ S. Duygu Sütekin ${ }^{3,4} \cdot$ Saliha B. Kurt ${ }^{2} \cdot$ Olgun Güven $^{3}$. Nurettin Sahiner ${ }^{1,2,5,6}$}

1 Department of Chemistry, Faculty of Science and Arts, Terzioglu Campus, Canakkale Onsekiz Mart University, 17100 Canakkale, Turkey

2 Nanoscience, and Technology Research and Application Center (NANORAC), Canakkale Onsekiz Mart University, Terzioglu Campus, 17100 Canakkale, Turkey

3 Department of Chemistry, Hacettepe University, Beytepe, 06800 Ankara, Turkey

4 UNAM-National Nanotechnology Research Center, Bilkent University, 06800 Ankara, Turkey

5 Department of Chemical and Biomolecular Engineering, University of South Florida, Tampa, FL 33620, USA

6 Department of Ophthalmology, Morsani College of Medicine, University of South Florida, 12901 Bruce B. Downs Blvd, MDC21, Tampa, FL 33612, USA 